\title{
Long intergenic non-coding RNA 00467 promotes lung adenocarcinoma proliferation, migration and invasion by binding with EZH2 and repressing HTRA3 expression
}

\author{
XIANGHAI WANG $^{1 *}$, HONGBING LIU $^{1 *}$, KAIKAI SHEN ${ }^{2}$, XIANHUI PAN ${ }^{2}$, \\ YUQING $\mathrm{WEI}^{3}$, TANGFENG LV ${ }^{1}$ and YONG SONG ${ }^{1}$ \\ ${ }^{1}$ Department of Respiratory Medicine, Jinling Clinical Medical College of Nanjing Medical University, \\ Nanjing, Jiangsu 210002; ${ }^{2}$ Department of Respiratory Medicine, Yijishan Hospital, \\ Wannan Medical College, Wuhu, Anhui 241001; ${ }^{3}$ Department of Respiratory Medicine, Jinling Hospital, \\ Nanjing University School of Medicine, Nanjing, Jiangsu 210002, P.R. China
}

Received October 19, 2018; Accepted April 8, 2019

DOI: $10.3892 / \mathrm{mmr} .2019 .10292$

\begin{abstract}
Long non-coding RNAs (IncRNAs) have been identified to serve an important role in the occurrence, development and metastasis of tumours. However, the role of linc00467 in lung adenocarcinoma (LAD) is unclear. In the present study, it was demonstrated that linc00467 expression was upregulated in human lung tumour tissues compared with normal tissues. In addition, high levels of linc00467 expression were associated with larger tumour sizes and later TNM stages. Functional experiments suggested that linc 00467 promoted LAD cell proliferation, migration and invasion, and inhibited apoptosis in vitro. Knockdown of linc00467 altered the expression of downstream genes, including HtrA serine peptidase 3 (HTRA3), and RNA immunoprecipitation and chromatin immunoprecipitation assays indicated that linc00467 recruited EZH2 to the HTRA3 promoter to inhibit its expression. Taken together, the results of the present study indicated that linc00467 served an oncogenic role in LAD tumourigenesis, suggesting that it may be used as a novel diagnostic biomarker and therapeutic target for LAD.
\end{abstract}

\section{Introduction}

The incidence and mortality of lung cancer are the highest among all malignant tumours (1). Non-small cell lung cancer (NSCLC)

Correspondence to: Dr Yong Song, Department of Respiratory Medicine, Jinling Clinical Medical College of Nanjing Medical University, 305 East Zhongshan Road, Nanjing, Jiangsu 210002, P.R. China

E-mail: yong_song6310@yahoo.com

"Contributed equally

Key words: long intergenic non-coding RNA, linc00467, lung adenocarcinoma, proliferation, migration, invasion, HtrA serine peptidase 3 is the primary pathological type of lung cancer, and the majority of tumours are lung adenocarcinomas (LAD). Although significant progress has been made in the diagnosis and treatment of lung cancer in recent years (2), the prognosis of lung cancer remains poor, and the 5-year survival rate is $<16 \%$ (3). Therefore, it is urgent that early diagnostic indicators and novel therapeutic targets for lung cancer be actively sought.

With the rapid development of whole-genome sequencing technology and bioinformatics methods, a large number of long non-coding RNAs (lncRNAs) have been identified. Previous studies have demonstrated that lncRNAs regulate gene expression at multiple levels and participate in the progression of various diseases (4-6). lncRNAs serve an important role in tumour progression and participate in the regulation of tumour cell proliferation, migration, invasion and differentiation $(7,8)$. These macromolecules may also be used as potential biomarkers and therapeutic targets for a number of types of tumours (9), and their potential value in lung cancer is gradually being revealed.

linc00467, which has 4 transcripts and a full length of $3,508 \mathrm{bp}$, belongs to the group of long intergenic non-coding RNAs and is located on lq32.3. At present, little is known about linc00467. Previous studies on neuroblastoma have identified that linc00467 may promote Wnt signalling pathway activation through a transacting mechanism, thereby promoting the proliferation of neuroblastoma (10). To the best of our knowledge, there have been no studies on the association between linc00467 and lung cancer at present.

Through RNA sequencing, HtrA serine peptidase 3 (HTRA3) was identified to be the downstream target gene of LAD in the present study. HTRA3 belongs to the conserved HTRA family of oligomeric serine proteases and has been demonstrated to inhibit tumour cell proliferation, migration and invasion. Previous studies have revealed that HTRA3 is downregulated in different types of tumours (11), and its upregulation may inhibit the growth of pancreatic cancer (12). In addition, a previous study demonstrated that downregulation of HTRA3 promoted lymph node metastasis in breast cancer (13). However, little is known about HTRA3 and linc00467 in LAD. 
The present study investigated the role of linc00467 in LAD. It was identified that linc00467 was markedly upregulated in LAD tissues. Knockdown of linc00467 resulted in the decreased proliferation, migration and invasion of LAD cells, while linc00467 overexpression increased LAD cell proliferation, migration and invasion. The results of the present study elucidated the crucial role of linc00467 in LAD progression and suggests that linc00467 may serve as a novel candidate target for LAD diagnosis and a potential therapeutic target in LAD.

\section{Materials and methods}

Gene expression data sets. The GSE19804, GSE19188, GSE30219, GSE27262 data sets from the Gene Expression Omnibus (GEO; http://www.ncbi.nlm.nih.gov/geo) and The Cancer Genome Atlas (TCGA) TANRIC database (http://ibl. mdanderson.org/tanric/_design/basic/query.html) were analysed using bioinformatic methods. The gene expression analyses were assessed using a linear model with Limma package in R software (version 3.3.2) (14). Differentially expressed genes were identified using the threshold absolute fold change (FC) $>1.5$ and false discovery rate $<0.05$ as cut-offs.

RNA transcriptome sequencing. For RNA-Seq, transcript alignments were conducted by HISAT2 (15) (version 2.0.5), assembly and quantification were conducted by StringTie $(16,17)$ (version 1.3.3b), and differential expression analyses were conducted based on the negative binomial distributions with edge $\mathrm{R}$ package in $\mathrm{R}$ software (version 3.18.1). Differential expression genes were identified as the threshold $|\log 2(\mathrm{FC})|>1$ and FDR $<0.05$. RNA transcriptome sequencing was performed by Novogene Bioinformatics Technology Co. Ltd.

Tissue samples and clinical data collection. A total of 35 paired LAD and normal lung tissues were obtained from patients (10 females and 25 males) who underwent primary surgical resection at the Jinling Clinical Medical College of Nanjing Medical University (Nanjing, China) from January 2015 to December 2016. The median age was 64 years and the range from 38 to 83 years. No treatments were conducted in these patients prior to surgery, and all tissues were immersed in RNALater stabilization solution (Qiagen $\mathrm{GmbH}$ ) and stored at $-80^{\circ} \mathrm{C}$. All patients with LAD were diagnosed according to histopathological evaluation, which was based on the 2011 International Association for the Study of Lung Cancer/American Thoracic Society/European Respiratory Society: international multidisciplinary classification of lung adenocarcinoma (18). The study protocol and methods were approved by the Research Ethics Committee of Jinling Clinical Medical College of Nanjing Medical University. All of the participants provided written informed consent form and agreed to the use of their samples in scientific research.

Cell lines. A total of 3 LAD H1299, A549, PC9 and 16HBE cell lines were purchased from the Shanghai Institute of Biochemistry and Cell Biology, Chinese Academy of Sciences. H1299 and A549 cells were maintained in RPMI-1640 medium (Gibco; Thermo Fisher Scientific, Inc.). PC9 and 16HBE cells were cultured in Dulbecco's modified Eagle's medium (Gibco; Thermo Fisher Scientific, Inc.). Both media were supplemented with $10 \%$ foetal bovine serum (FBS, HyClone; GE Healthcare Life Sciences). All of the cells were grown in a humidified atmosphere at $37^{\circ} \mathrm{C}$ with $5 \% \mathrm{CO}_{2}$.

RNA isolation and reverse transcription quantitative polymerase chain reaction ( $R T-q P C R)$ analyses. Total RNA was isolated from cultured LAD cells or frozen tissue samples using TRIzol ${ }^{\circledR}$ reagent (Thermo Fisher Scientific, Inc.). cDNA was synthesized using a Reverse Transcription kit (Takara Biotechnology Co., Ltd.). RT-qPCR assays were performed using a SYBR Premix Ex Taq II kit (Takara Biotechnology Co., Ltd.), and the target gene expression values were normalized to the expression of GAPDH. The results were analysed based on the comparative cycle threshold $(\mathrm{Cq})\left(2^{-\Delta \mathrm{Cq}}\right.$ or $\left.2^{-\Delta \Delta \mathrm{Cq}}\right)$ methods (19). The primer sequences are listed in Table SI.

Transfection of LAD cells. Small interfering RNAs (siRNAs; si-linc00467 1\#, si-linc00467 2\# and si-linc00467 3\#) and plasmid vectors (pcDNA3.1 and pcDNA3.1-linc00467) were designed and synthesized by Shanghai GenePharma Co., Ltd., and the empty pcDNA3.1 vector was used as the control. The concentrations of siRNA and plasmids were $50 \mu \mathrm{M}$ and $2 \mu \mathrm{g} / \mathrm{ml}$, respectively. siRNAs were transfected into cells using HiPerFect Transfection Reagent (Qiagen $\mathrm{GmbH}$ ). The plasmid vectors were transfected into cells using X-tremeGENE HP DNA transfection reagent (Roche Diagnostics). After $48 \mathrm{~h}$ of incubation in a humidified atmosphere at $37^{\circ} \mathrm{C}$ with $5 \% \mathrm{CO}_{2}$, the cells were harvested for subsequent experiments. Short hairpin RNA (shRNA) lentiviruses (linc00467 shRNA, control shRNA) were also designed and synthesized by Shanghai GenePharma Co., Ltd. The LV3 lentiviral vector (Shanghai GenePharma Co., Ltd.) to express shRNA via the H1 promoter. Synthetic oligonucleotide primers [forward (5'-GATCCG CTGGCAAATATGAAGGTATTCAAGAGATACCTTCAT ATTTGCCAGCTTTTTTG-3') and reverse (5'AATTCA AAAAAGCTGGCAAATATGAAGGTATCTCTTGAATAC CTTCATATTTGCCAGCG-3')], and the shRNA sequence expressed by the vector were sheared to form a target sequence 5'-GCTGGCAAATATGAAGGTA-3'. A fragment targeting linc00467 (5'-GCTGGCAAATATGAAGGTA-3') inserted into a lentiviral vector was used as linc00467-shRNA, and a non-targeting fragment (5'-TTCTCCGAACGTGTCACGT-3') inserted into a lentiviral vector was used as control-shRNA. The shRNA lentiviruses were transfected into cells in the presence of $2 \mu \mathrm{g} / \mathrm{ml}$ Polybrene, and linc00467-shRNA-transfected cells were screened with $1,2,4$ or $8 \mu \mathrm{g} / \mathrm{ml}$ puromycin for 8 days post-transfection. siRNA was used in the preliminary functional experiments, whereas the experiments investigating the mechanisms of action required longer culture times. Therefore, shRNA was used in the later mechanism studies. The primer sequences are listed in Table SII.

Nuclear and cytoplasmic RNA isolation. Cytoplasmic and nuclear RNA were separated and purified using a PARIS kit (Thermo Fisher Scientific, Inc.), following the manufacturers' protocol. The buffer was pre-cooled using ice and added to the cultured cells; lysate was then collected in an enzyme-free Eppendorf (EP) tube, and cytoplasmic lysate was collected by centrifugation at $10,000 \mathrm{x} g$ for $1 \mathrm{~min}$ at room temperature into an enzyme-free EP tube. Cell disruption buffer was then added, and the nuclear lysate 
was collected by centrifugation at $10,000 \mathrm{x}$ g for $1 \mathrm{~min}$ at room temperature into an enzyme-free EP tube. An equal volume of $2 \mathrm{X}$ lysis/binding solution (Invitrogen; Thermo Fisher Scientific, Inc.) and absolute ethanol were added into each tube, following which the mixture was transferred into an enzyme-free EP tube and centrifuged at $10,000 \mathrm{x}$ g for $1 \mathrm{~min}$ at room temperature. The liquid flow-through was then discarded, 3 wash steps were performed and $95-100^{\circ} \mathrm{C}$ Elution Solution (Qiagen $\mathrm{GmbH}$ ). was added to obtain RNA. GAPDH and U6 were used as internal controls, and RT-qPCR was used to measure the expression of linc00467 in the nucleus and cytoplasm.

Cell proliferation assays. An MTT assay was used to measure cell proliferation using a Cell Proliferation Reagent kit I (Roche Diagnostics). After $48 \mathrm{~h}$ of transfection, the cells were plated on 96-well plates at a density of 3,000 cells per well. The 96-well culture plates were taken at $0,24,48,72$ and $96 \mathrm{~h}$, respectively, and proliferation was detected at the corresponding time points. MTT $(20 \mu \mathrm{l})$ was added into each well, and the cells were incubated for $4 \mathrm{~h}$ in a humidified atmosphere containing $5 \% \mathrm{CO}_{2}$ at $37^{\circ} \mathrm{C}$. The reaction was then terminated by removal of the supernatant, and $150 \mu \mathrm{l}$ dimethyl sulfoxide (DMSO) solution was added to dissolve the purple formazan crystals. The plate was shaken for $20 \mathrm{~min}$ to promote the dissolution of the crystals. The absorbance was measured at a wavelength of $490 \mathrm{~nm}$ using a microplate reader, and cell proliferation was analysed based on the absorbance value. The clonogenic ability of the LAD cells was examined using the colony formation method. The transfected cells were digested with $0.25 \%$ trypsin and thoroughly pipetted into a single-cell suspension. Following cell counting, the cells were densely seeded $(1,000$ cells/well) in a 6 -well culture plate, evenly dispersed and plated at $37^{\circ} \mathrm{C}$. After 4 days, the supernatant was discarded and replaced with new complete medium. When the colonies were visible to the naked eye, the culture was terminated. The supernatant was aspirated, the plates were carefully rinsed with PBS, and cells were fixed with $4 \%$ paraformaldehyde for $15 \mathrm{~min}$ at room temperature. Subsequent to removal of the fixative, $1 \mathrm{ml} 0.1 \%$ crystal violet stain solution was added into each well for $15 \mathrm{~min}$ at room temperature, following which the stain was discarded. The remaining stain was washed off with PBS, and the plates were dried at room temperature. The number of colonies $>10$ cells was counted using an optical light microscope at x100 magnification (Olympus, Tokyo, Japan), and statistical analyses were performed.

Flow cytometry(FCM) apoptosisassay. The cells were densely seeded $\left(2 \times 10^{5}\right.$ cells/well) in a 6-well culture plate. H1299, A549 and PC9 cells transfected with si-NC/si-linc00467 or empty vector/pcDNA3.1-linc00467 were collected $48 \mathrm{~h}$ after transfection. The cells were diluted with the cell binding buffer (BD Pharmingen; BD Biosciences) and stained with Annexin V-allophycocyanin (APC) and 7 amino-actinomycin (7-AAD) in the dark at room temperature for $15 \mathrm{~min}$, prior to being analysed with a flow cytometer (FACScan ${ }^{\circledR}$; BD Biosciences). A tube containing only Annexin V-APC and 7-AAD was used as the negative control. The data were analysed using CellQuest software (version 6.0 (BD Biosciences).

Transwell assay. Transwell chambers (EMD Millipore) were used for cell migration and invasion assays. For the migration assay, $3 \times 10^{4}$ cells in $300 \mu 1$ serum-free medium were seeded into the top chamber of each insert, and $700 \mu 1$ medium supplemented with $10 \%$ FBS was added into the lower chamber. For the invasion assay, the upper chamber membrane was first uniformly coated with Matrigel (BD Biosciences) at $37^{\circ} \mathrm{C}$ for $24 \mathrm{~h}$. Then, $1 \times 10^{5}$ cells in $300 \mu 1$ serum-free medium were placed into the top chamber of each insert, and $700 \mu 1$ medium supplemented with $10 \%$ FBS was added into the lower chamber. Following incubation of the A549 and H1299 cells at $37^{\circ} \mathrm{C}$ for $48 \mathrm{~h}$, and the PC9 cells were incubated at $37^{\circ} \mathrm{C}$ for $24 \mathrm{~h}$, the cells in the top chamber were removed, and cells that had migrated or invaded through the membrane were stained for $15 \mathrm{~min}$ with $0.1 \%$ crystal violet at $37^{\circ} \mathrm{C}$. The stained cells were counted under a light microscope (magnification, x100; Olympus Corporation).

RNA-protein interaction prediction. The probability of an interaction between linc00467 and RBPs was determined using an lncRNA prediction website (http://annolnc.cbi.pku. edu.cn/index.jsp). The sequence of linc00467 was entered into the AnnoLnc database and into the protein interaction page; from this, the interaction score between IncRNA and protein could be predicted.

Western blot analysis. Cells were collected, washed twice with ice-cold PBS and lysed in $100 \mu \mathrm{l}$ RIPA buffer (Servicebio) supplemented with protease inhibitor (Sigma-Aldrich; Merck $\mathrm{KGaA}$ ) for $30 \mathrm{~min}$, and a bicinchoninic protein assay kit (CWBIO Corporation) was used to detect the protein concentration. Total protein samples $(20 \mu \mathrm{g})$ were electrophoresed on $10 \%$ SDS-PAGE and transferred onto polyvinylidene fluoride membranes (EMD Millipore). Following blocking with $5 \%$ milk for $1 \mathrm{~h}$ at room temperature, the membranes were incubated overnight at $4^{\circ} \mathrm{C}$ with primary antibody EZH2 (1:1,000; ab191250; Abcam) and HTRA3 (1:1,000; ab227463; Abcam); GAPDH was used as the loading control $(1: 3,000$; ab181602; Abcam). The blots were extensively washed five times with TBST $(0.5 \%$ Tween-20) and incubated with horseradish peroxidase-conjugated goat anti-rabbit secondary antibody (1:3,000; ab150081; Abcam) for $1 \mathrm{~h}$ at room temperature. Following washing, an ECL chromogenic substrate and densitometry using Quantity One software (version 4.6.9, Bio-Rad Laboratories, Inc.) were used to measure the blots.

RNA immunoprecipitation (RIP) assay. The RNA immunoprecipitation (RIP) assay was performed using a Magna RIP RNA-Binding Protein Immunoprecipitation kit (17-701; EMD Millipore) in accordance with the manufacturer's protocol. Whole-cell extract from A549 and H1299 cells was used for immunoprecipitations by using RIP lysis buffer (CS203176; EMD Millipore). For each immunoprecipitation reaction, $50 \mu \mathrm{l}$ protein A Sepharose beads and $5 \mu \mathrm{g}$ antibody against histone-lysine N-methyltransferase EZH2 (ab191250; Abcam) were used. Immunoprecipitation was performed using a relevant antibody to the DNase-treated extract and incubating at $4^{\circ} \mathrm{C}$ overnight. Then samples were sequentially treated with Proteinase K and RQ1 RNase-free DNase to digest protein and genomic DNA, respectively. Purified RNA samples were re-suspended in water and stored at $80^{\circ} \mathrm{C}$. Finally, the purified RNA was used for RT-qPCR. 

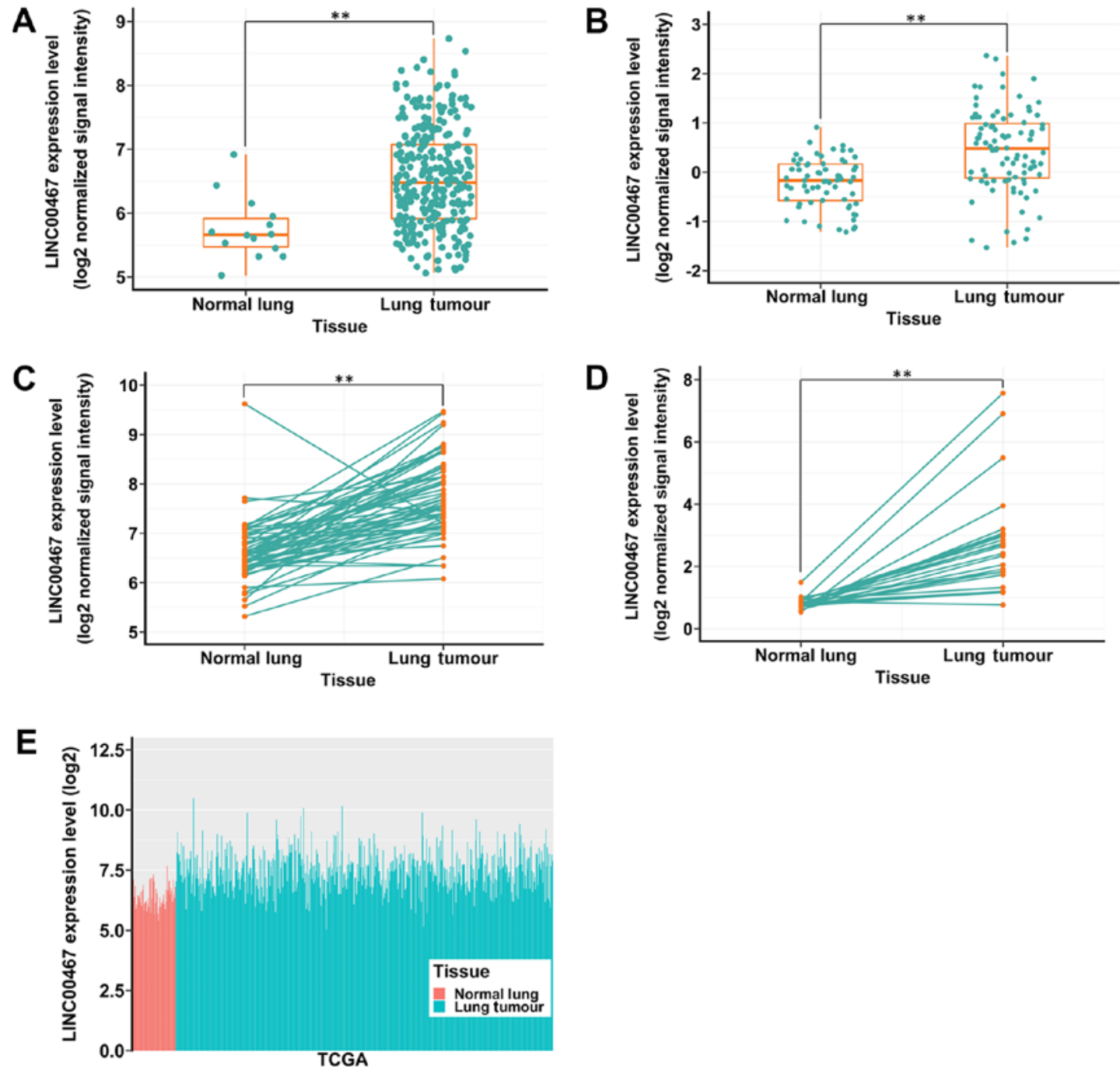

Figure 1. Bioinformatic analysis of the relative expression levels of linc00467 in LAD and normal tissues. (A-D) The relative expression of linc00467 was increased in LAD tissues compared with normal tissues based on the 4 Gene Expression Omnibus datasets: (A) GSE30219; (B) GSE19188; (C) GSE19804; and (D) GSE27262. ${ }^{* *} \mathrm{P}<0.01$. (E) The relative expression of linc00467 in LAD tissues compared with normal tissues was analysed using the TCGA database. TCGA data also indicated that linc00467 expression was upregulated in lung cancer tissues compared with normal tissues. LAD, lung adenocarcinoma; linc, long intergenic non-coding RNA; TCGA, The Cancer Genome Atlas.

Chromatin immunoprecipitation (ChIP) assay. A549 and H1299 cells were cross-linked with $1 \%$ formaldehyde for $10 \mathrm{~min}$ at room temperature. Crosslinking was halted by addition of $125 \mathrm{mM}$ glycine. Pellets were washed twice with complete proteinase inhibitor cocktail (Roche Diagnostics) in PBS, and then resuspended in $400 \mu 1$ SDS lysis buffer (Sigma-Aldrich; Merck KGaA) for $30 \mathrm{~min}$. Then, $2 \%$ of supernatant was saved as input and $100 \mu \mathrm{l}$ of supernatant was incubated with $5 \mu \mathrm{g}$ EZH2 (ab191250; Abcam) or IgG (ab172730; Abcam) antibodies for 16 hours at $4^{\circ} \mathrm{C}$. Then $30 \mu \mathrm{l}$ of protein $\mathrm{G}$ magnetic beads (Thermo Fisher Scientific, Inc.) was added to each IP reaction and incubated for $2 \mathrm{~h}$ at $4^{\circ} \mathrm{C}$ with rotation. Immunoprecipitates were then processed with a series of washes and the cross-linking reversed. The DNA was purified by phenol/chloroform/isoamyl extraction and RT-qPCR was performed as aforementioned. The sequences of the ChIP primers for the HTRA3 promoter region are listed in Table SI.

Statistical analysis. All of the statistical analyses were performed using SPSS 18.0 software (SPSS, Inc.). P $<0.05$ was considered to indicate a statistically significant difference, and $\mathrm{P}<0.01$ was considered to indicate a highly statistically significant difference. Data are presented as mean \pm standard deviation. A two-tailed Student's t-test was applied to compare differences between two groups. The comparison of multiple groups were performed using one-way analysis of variance, and the post-hoc multiple comparisons were performed using the Least Significant Difference test.

\section{Results}

Expression profile of linc00467 in LAD tissues from GEO and TCGA datasets. A total of 4 microarray datasets (GSE19804, GSE19188, GSE30219 and GSE27262) obtained from the GEO were used to analyse linc00467 expression in lung cancer tissues and normal tissues. It was identified that linc00467 was upregulated in the 4 data sets (Fig. 1A-D). In addition, TCGA data also indicated that linc00467 expression was upregulated in lung cancer tissues compared with normal tissues (Fig. 1E). 
Table I. Associations between linc00467 expression and clinicopathological parameters of lung adenocarcinoma.

\begin{tabular}{|c|c|c|c|}
\hline \multirow[b]{2}{*}{ Clinicopathological parameters } & \multirow[b]{2}{*}{ Number of patients } & linc00467 expression $\left(2^{-\Delta \mathrm{Cq}}\right)$ & \multirow[b]{2}{*}{ P-value } \\
\hline & & Median \pm standard deviation & \\
\hline Sex & & & 0.963 \\
\hline Male & 25 & $0.530 \pm 0.205$ & \\
\hline Female & 10 & $0.533 \pm 0.202$ & \\
\hline Age, years & & & 0.601 \\
\hline$\leq 65$ & 23 & $0.544 \pm 0.120$ & \\
\hline$>65$ & 12 & $0.506 \pm 0.210$ & \\
\hline Size of tumour, $\mathrm{cm}$ & & & 0.013 \\
\hline$\leq 3$ & 23 & $0.471 \pm 0.173$ & \\
\hline$>3$ & 12 & $0.645 \pm 0.209$ & \\
\hline Differentiation & & & 0.637 \\
\hline Well/moderate & 24 & $0.520 \pm 0.199$ & \\
\hline Poor & 11 & $0.555 \pm 0.213$ & \\
\hline Lymph node metastasis (pN) & & & 0.253 \\
\hline N0 & 16 & $0.490 \pm 0.117$ & \\
\hline N1-N3 & 19 & $0.565 \pm 0.250$ & \\
\hline TNM stage & & & 0.021 \\
\hline $\mathrm{I} / \mathrm{II}$ & 25 & $0.482 \pm 0.170$ & \\
\hline III & 10 & $0.653 \pm 0.230$ & \\
\hline Smoking & & & 0.467 \\
\hline Yes & 22 & $0.550 \pm 0.218$ & \\
\hline No & 13 & $0.498 \pm 0.173$ & \\
\hline
\end{tabular}

linc, long intergenic non-coding RNA; TNM, tumour node metastasis.

linc00467 is upregulated in LAD tissues and is associated with the clinical characteristics of LAD. To validate the GEO and TCGA results, RT-qPCR assays were used to measure linc00467 expression in 35 paired LAD and adjacent normal lung tissues. The relative expression of lncRNA was calculated using the $\mathrm{Cq}$ value $\left(2^{-\Delta \mathrm{Cq}}\right)$ method. The expression level of linc00467 in LAD tissues was increased compared with that in adjacent normal lung tissues $(\mathrm{P}<0.001$; Fig. $2 \mathrm{~A})$. Then, the association between linc00467 expression and patients' clinical characteristics were evaluated (Table I). The linc00467 expression levels were significantly increased in patients with larger tumours compared with smaller tumours ( $\mathrm{P}=0.013$; Fig. $2 \mathrm{~B})$, and in those with more advanced TNM stages $(\mathrm{P}=0.021$; Fig. 2C). However, there were no significant associations between linc00467 expression and other clinical parameters, including age, sex, differentiation, lymph node metastasis and smoking history.

linc00467 promotes LAD cell proliferation by inhibiting apoptosis in vitro. To investigate the function of linc00467 in LAD cells, its expression levels in the human bronchial epithelial 16HBE cell line and in 3 human LAD A549, PC9 and H1299 cell lines were assessed using RT-qPCR. A549 and H1299 cells expressed increased levels of linc00467 compared with 16HBE cells, while the PC9 cells expressed relatively decreased linc00467 levels compared with A549 and H1299 cells (Fig. 3A). Therefore, linc00467 was knocked down with siRNA in the A549 and H1299 cell lines and overexpressed in PC9 cell lines. A localization assay for linc00467 in cells indicated that linc00467 was localized in the nucleus and cytosol but was localized to a greater extent in the nucleus (Fig. 3B-D). The results of the linc00467 knockdown assay in the A549 and H1299 cells by transfection with siRNAs are presented in Fig. 3E and F; 'si-linc00467 1\#' exhibited the best knockdown efficiency, so it was used for subsequent functional experiments. linc00467 expression was upregulated in PC9 cells by transfection with pcDNA3.1-linc00467 (Fig. 3G).

The role of linc00467 in LAD development was next examined. linc00467 was knocked down in A549 and H1299 by transfection with siRNAs and overexpressed in PC9 with pcDNA3.1-linc00467. The MTT assays indicated that A549 and H1299 cell viability was decreased following knockdown of linc00467 (Fig. 4A and B), while cell viability was increased in pcDNA3.1-linc00467-treated PC9 cells (Fig. 4C). The colony formation ability of A549 and H1299 cells was consistently and significantly impaired following linc00467knockdown, while linc00467 overexpression increased PC9 cell colony formation ability (Fig. 4D-F). Overall, linc00467 served as an oncogene to promote LAD cell proliferation. Flow cytometric analyses indicated that linc00467 knockdown significantly increased the levels of apoptosis in A549 and H1299 cells (Fig. 5A and B). By contrast, linc00467 

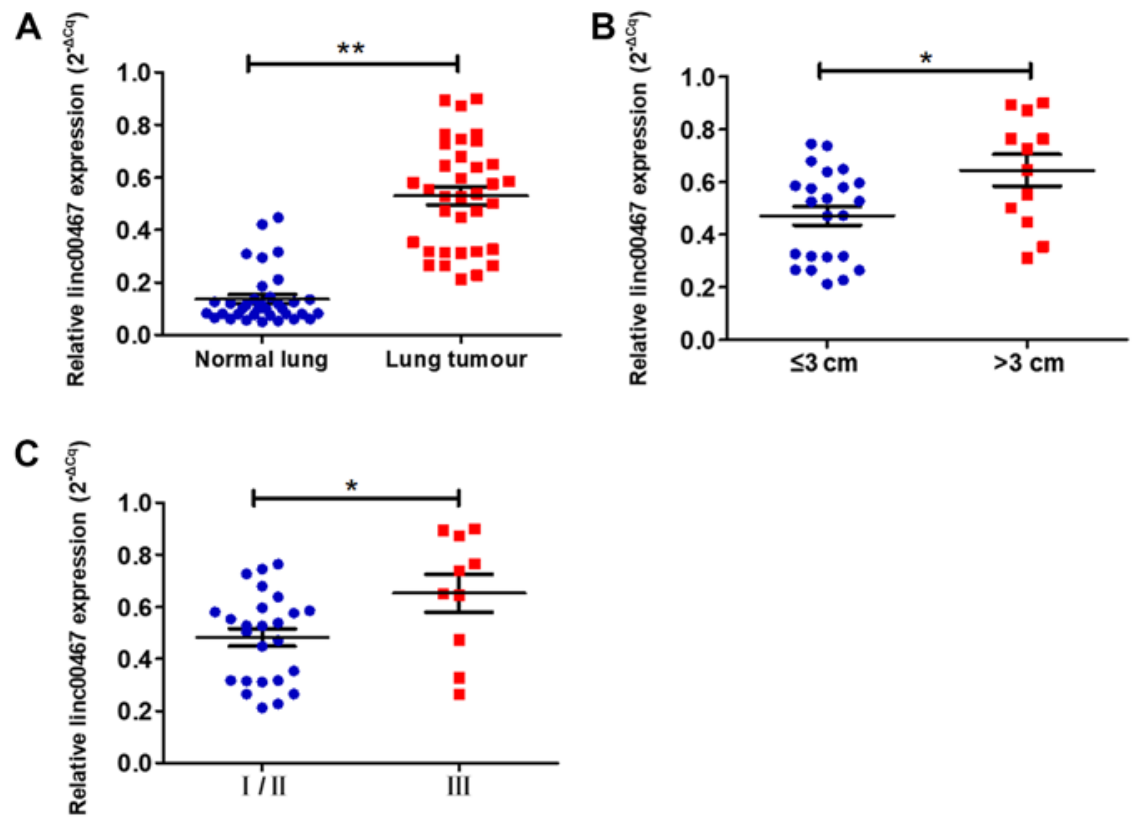

Figure 2. linc00467 is upregulated in LAD tissues. (A) linc00467 expression in LAD ( $\mathrm{n}=60)$ compared with matched adjacent normal tissues ( $\mathrm{n}=60)$ was examined by reverse transcription quantitative polymerase chain reaction, and linc00467 was clearly upregulated in lung cancer tissues. (B) linc00467 expression was increased in tumours with a maximum diameter $>3 \mathrm{~cm}$. (C) linc00467 expression was increased in stage III tumours. ${ }^{*} \mathrm{P}<0.05$ and ${ }^{* * *} \mathrm{P}<0.01$. linc, long intergenic non-coding RNA; LAD, lung adenocarcinoma.

A

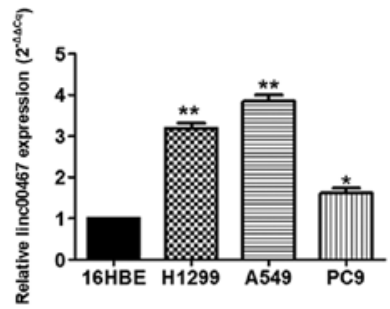

D

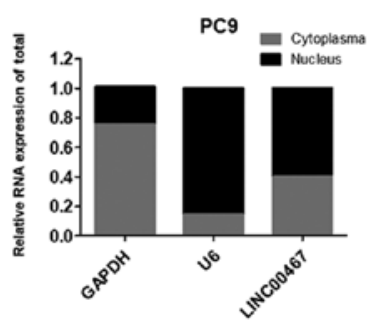

B

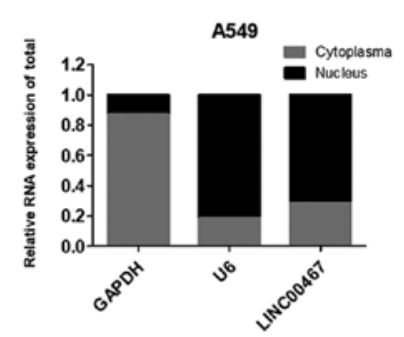

E

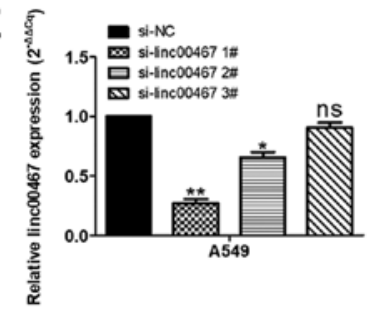

C

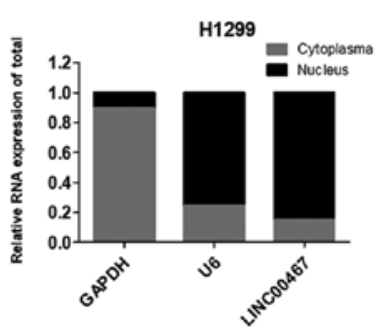

$\mathbf{F}$

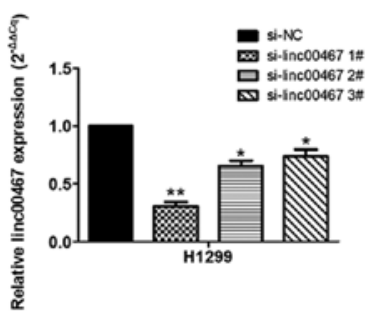

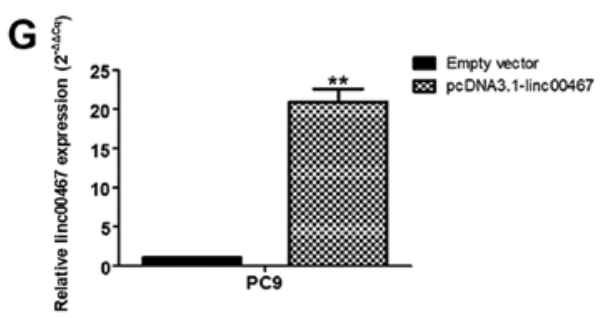

Figure 3. Abundance of linc00467 in LAD cells. (A) linc00467 expression was analysed by RT-qPCR in 3 LAD H1299, A549 and PC9 cell lines and in the normal bronchial epithelial 16HBE cell line. A549 and H1299 cells expressed increased levels of linc00467 compared with the 16HBE cells, while PC9 cells expressed relatively decreased linc00467 levels compared with the A549 and H1299 cells. (B-D) RT-qPCR was performed to detect the relative cytoplasmic and nuclear linc00467 levels in (B) A549, (C) H1299 and (D) PC9 cells. GAPDH was used as a cytoplasmic expression control, and U6 was used as a nuclear expression control. linc00467 was localized in of the nucleus and cytosol but was localized to a greater extent in the nucleus. (E and F) Relative expression of linc00467 in (E) A549 and (F) H1299 cells transfected with siRNAs. linc00467 was knocked down in A549 and H1299 cells by transfection with siRNAs. (G) Relative expression of linc00467 in PC9 cells transfected with the pcDNA3.1-linc00467 vector. linc00467 was overexpressed in PC9 cells via transfection with the pcDNA3.1-linc00467 vector. The data were obtained from at least 3 independent experiments and are presented as the mean \pm standard deviation. ${ }^{*} \mathrm{P}<0.05$ and ${ }^{* *} \mathrm{P}<0.01$. linc, long intergenic non-coding RNA; LAD, lung adenocarcinoma; RT-qPCR, reverse transcription quantitative polymerase chain reaction; siRNA; small interfering RNA; ns, not significant; NC, negative control. 


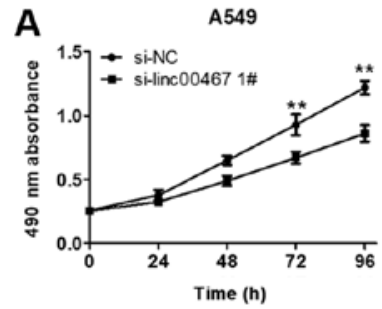

D
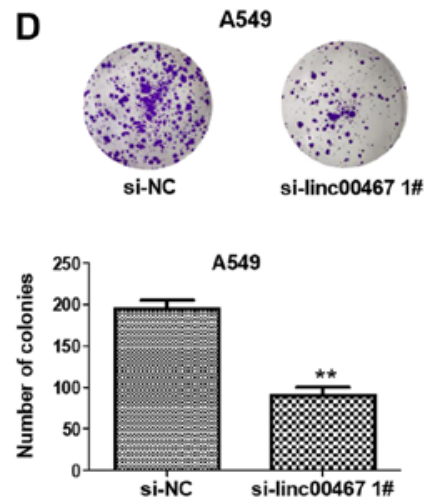

B

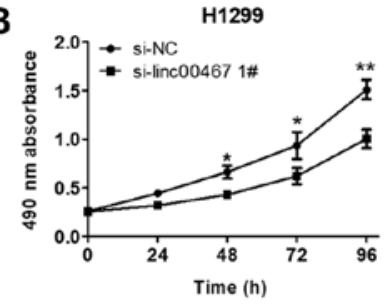

E
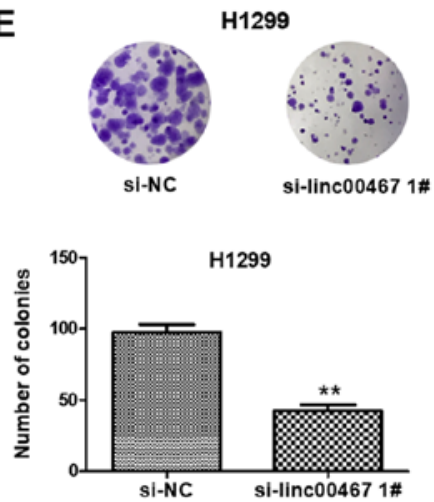

C

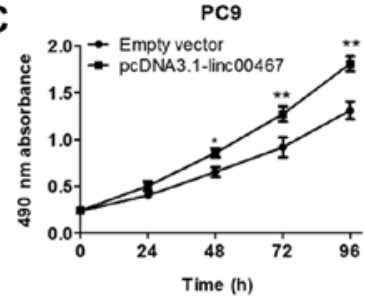

$\mathbf{F}$
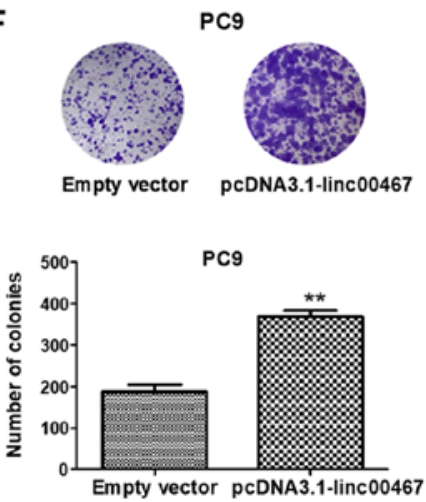

Figure 4. Effects of linc00467 on LAD cell proliferation in vitro. (A-C) MTT assays were performed to determine the viability of si-linc00467-transfected (A) A549 and (B) H1299 cells or (C) pcDNA3.1-linc00312-transfected PC9 cells. The MTT assays indicated that A549 and H1299 cell viability was decreased following knockdown of linc00467, while cell viability increased in pcDNA3.1-linc00467-treated PC9 cells. (D-F) Colony formation assays were conducted to determine the proliferative ability of transfected LAD cells. The colony formation ability of (D) A549 and (E) H1299 cells was significantly impaired following linc00467 knockdown, while (F) linc00467 overexpression increased PC9 cell colony formation ability. The data were obtained from at least 3 independent experiments and are presented as the means \pm standard deviation. Magnification, $\mathrm{x} 100$. ${ }^{*} \mathrm{P}<0.05$ and ${ }^{* *} \mathrm{P}<0.01$. linc, long intergenic non-coding RNA; LAD, lung adenocarcinoma; siRNA, small interfering; NC, negative control.

A

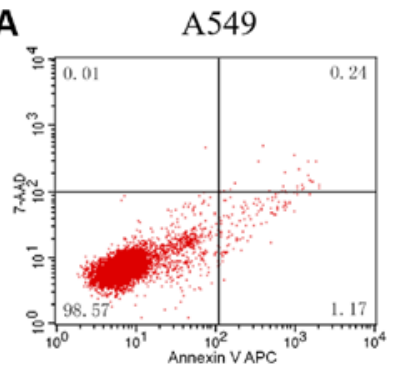

si-NC

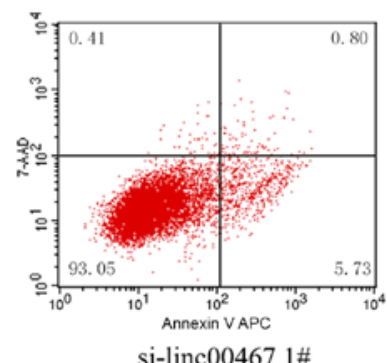

si-linc00467 1\#

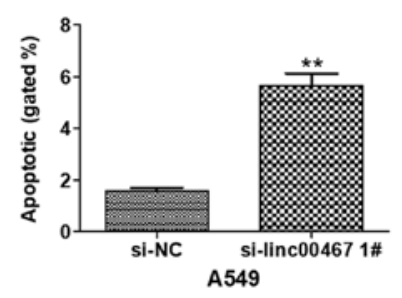

B

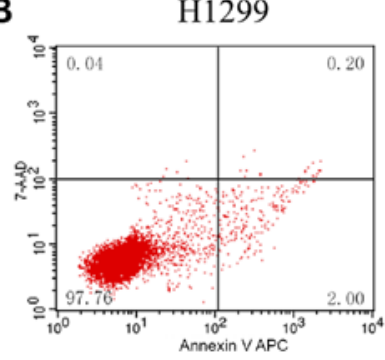

si-NC

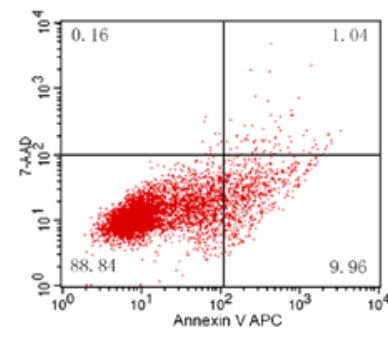

si-linc00467 1\#

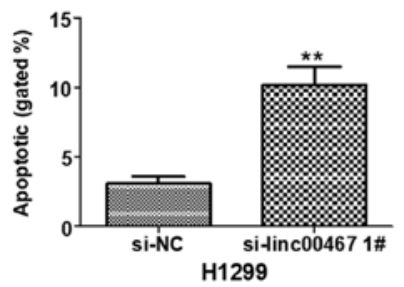

C

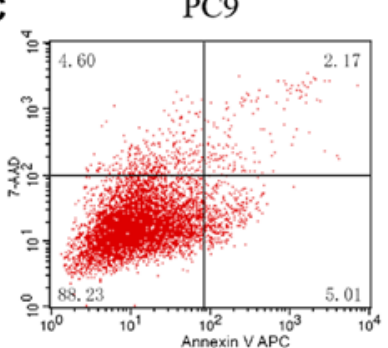

Empty vector

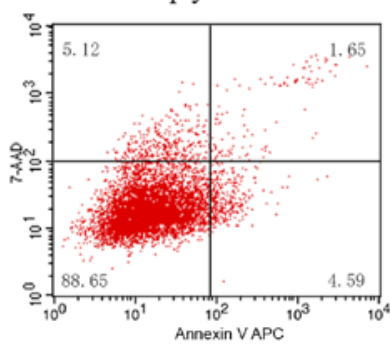

pcDNA3.1-linc00467

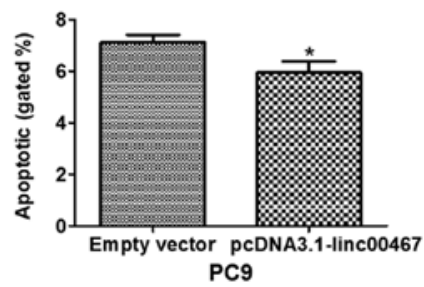

Figure 5. Effect of linc00467 on LAD apoptosis. Flow cytometry was used to analyse the apoptotic rates of si-linc00467-transfected A549 and H1299 cells and pcDNA3.1-linc00467-transfected PC9 cells. (A and B) Flow cytometric analyses indicated that linc00467 knockdown significantly increased apoptosis in (A) A549 and (B) $\mathrm{H} 1299$ cells. (C) linc00467 overexpression decreased PC9 apoptosis. The data were obtained from at least 3 independent experiments and are presented as the mean \pm standard deviation. ${ }^{*} \mathrm{P}<0.05$ and ${ }^{* *} \mathrm{P}<0.01$. linc, long intergenic non-coding RNA; LAD, lung adenocarcinoma; siRNA, small interfering; NC, negative control. 
A

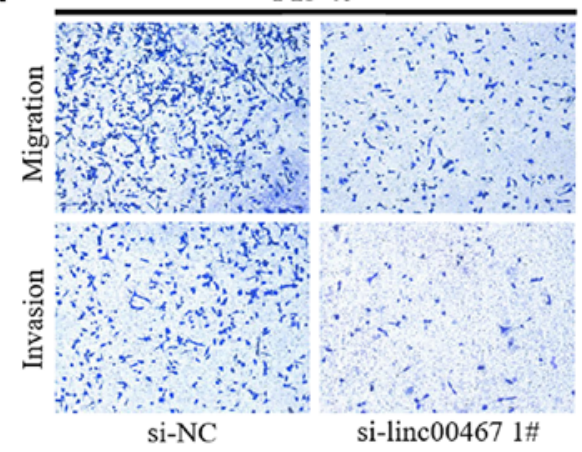

B

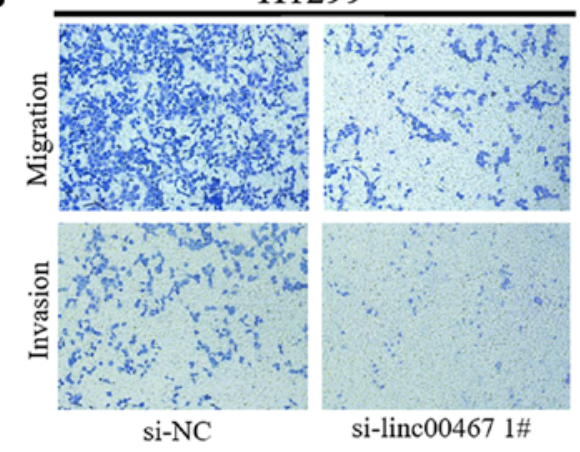

C

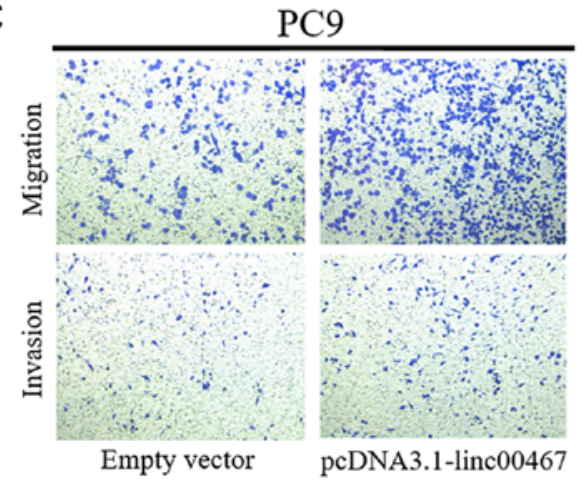

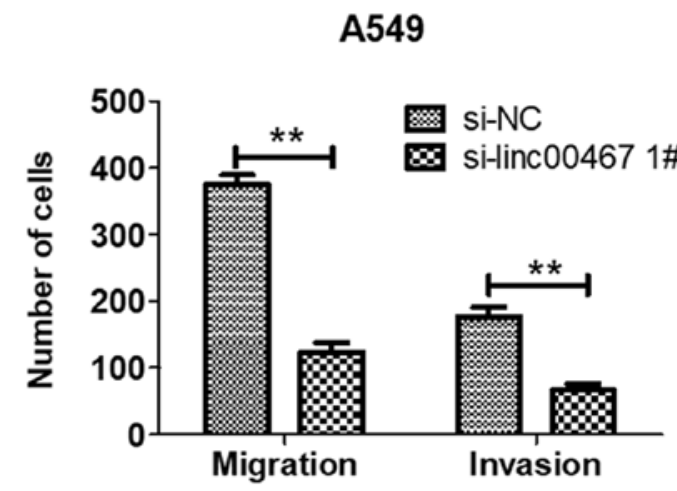

H1299
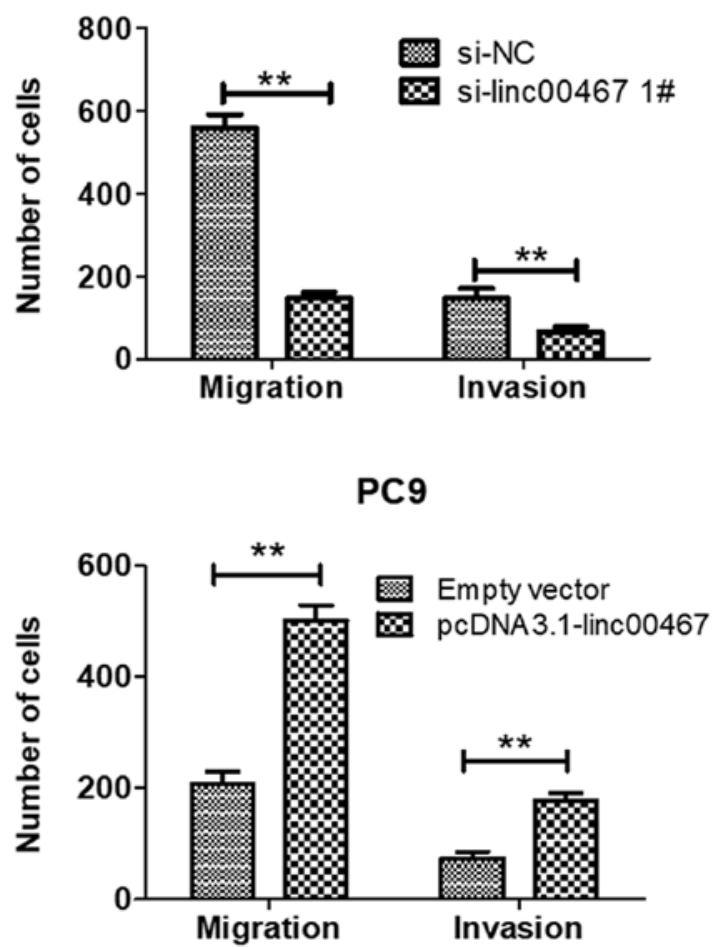

Figure 6. Effect of linc00467 on LAD cell migration and invasion ability. Transwell assays were conducted to observe the migration and invasion ability of si-linc00467-transfected A549 and H1299 cells and pcDNA3.1-linc00467-transfected PC9 cells. (A and B) linc00467 knockdown significantly suppressed the migration and invasion ability of (A) A549 and (B) H1299 cells. (C) linc00467 overexpression increased the migration and invasion ability of PC9 cells. The data were obtained from at least 3 independent experiments and are presented as the mean \pm standard deviation. Magnification, $\mathrm{x} 100$. ${ }^{* *} \mathrm{P}<0.01$. linc, long intergenic non-coding RNA; LAD, lung adenocarcinoma; siRNA, small interfering RNA; NC, negative control.

overexpression decreased the levels of apoptosis in PC9 cells (Fig. 5C). The results confirmed that linc00467 promoted LAD cell proliferation by affecting LAD cell apoptosis.

linc00467 promotes LAD cell migration and invasion in vitro. As linc00467 was confirmed to promote LAD cell proliferation in vitro, its effects on LAD cell migration and invasion was additionally investigated. A Transwell assay was used to evaluate the biological effect of linc00467 on the LAD cell metastasis. linc00467 knockdown significantly suppressed the migratory and invasive abilities of A549 and H1299 cells (Fig. 6A and B), while linc00467 overexpression increased the migratory and invasive abilities of PC9 cells (Fig. 6C). These results suggested that linc00467 promoted the migration and invasion of LAD cells.
Gene expression profiling. linc00467 was knocked down in H1299 cells by transfection with shRNA lentiviruses. The knockdown efficiency of shRNA was verified by RT-qPCR (Fig. 7A and B). RNA transcriptome sequencing was used to identify genes that were differentially expressed between linc00467-knockdown H1299 and control cells. A total of 625 differentially expressed transcripts were identified using database analysis (471 upregulated and 154 downregulated transcripts, $\mid \log 2$ (FC)| $>1$ and FDR $<0.05$ ) (Fig. 8A and B). RT-qPCR was used to verify the expression of 6 randomly selected genes expression in A549 and H1299 cells, and the results were consistent with the RNA transcriptome sequencing results (Fig. 8C and D).

RNA transcriptome sequencing indicated that HTRA3 was upregulated to a greater extent in linc00467-depleted H1299 cells compared with the control cells. It was then additionally 


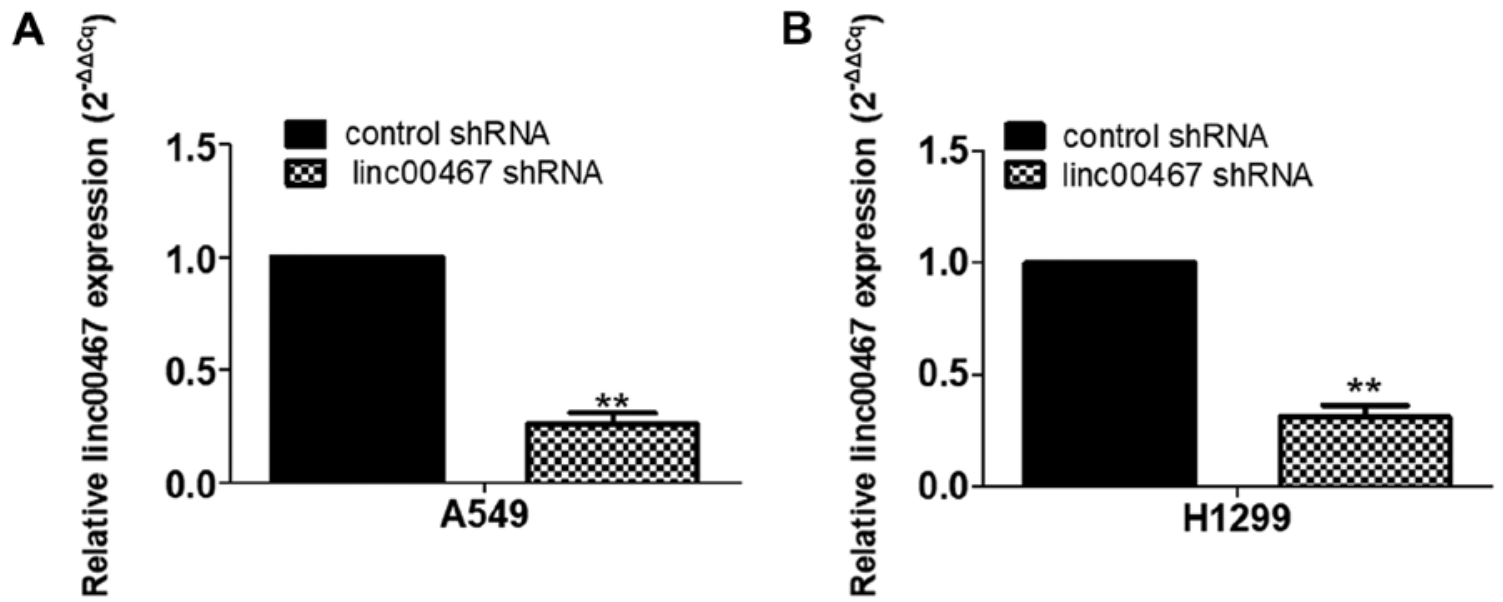

Figure 7. Relative expression of linc00467 in A549 and H1299 cells transfected with linc00467-shRNA. (A and B) linc00467 was knocked down in (A) A549 and (B) H1299 cells by transfection with linc00467-shRNA. ${ }^{* *} \mathrm{P}<0.01$. linc, long intergenic non-coding RNA; shRNA, short hairpin RNA.

A

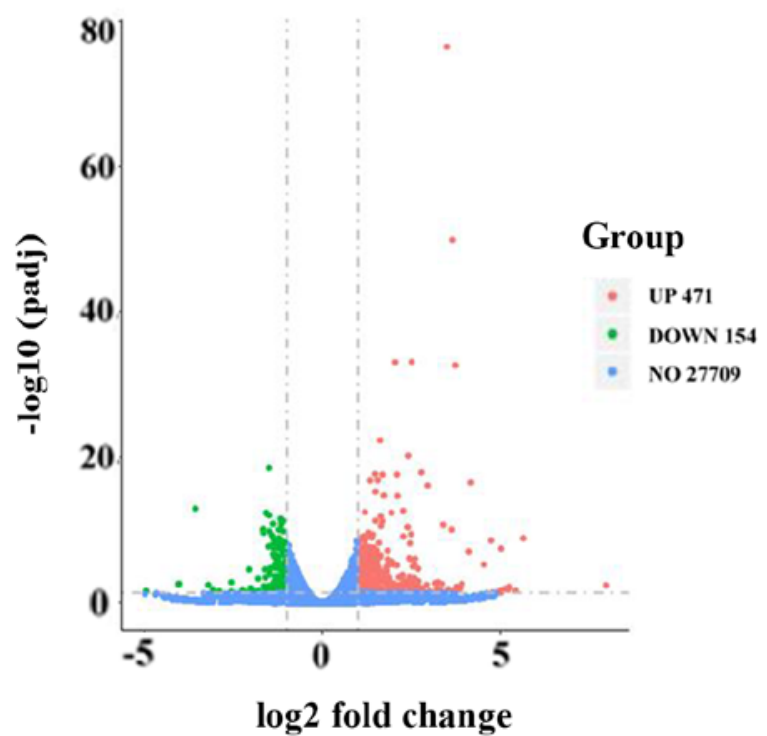

C

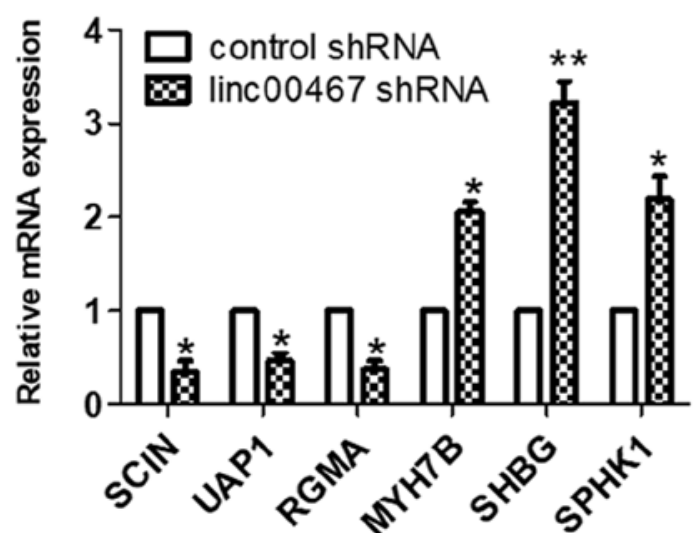

B

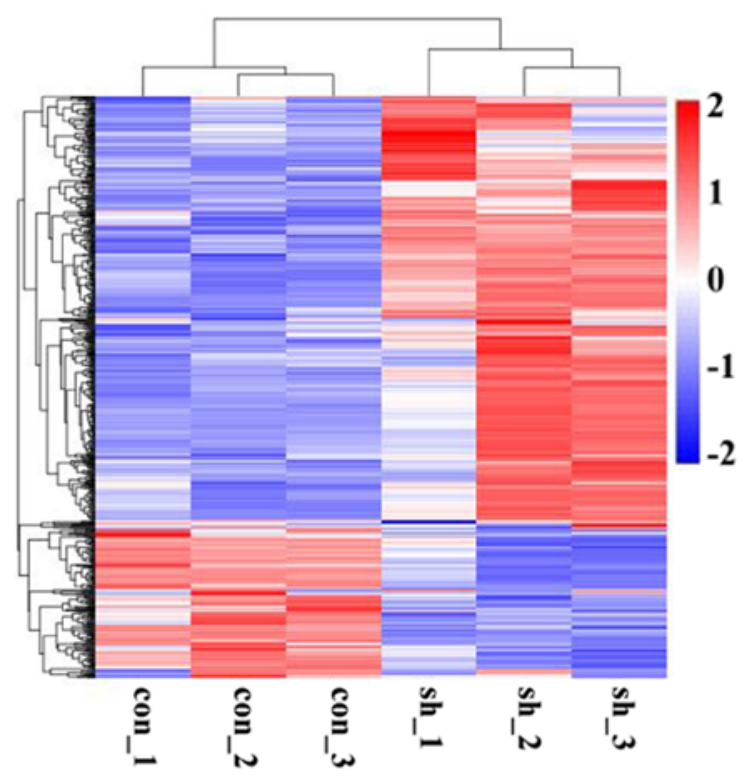

D

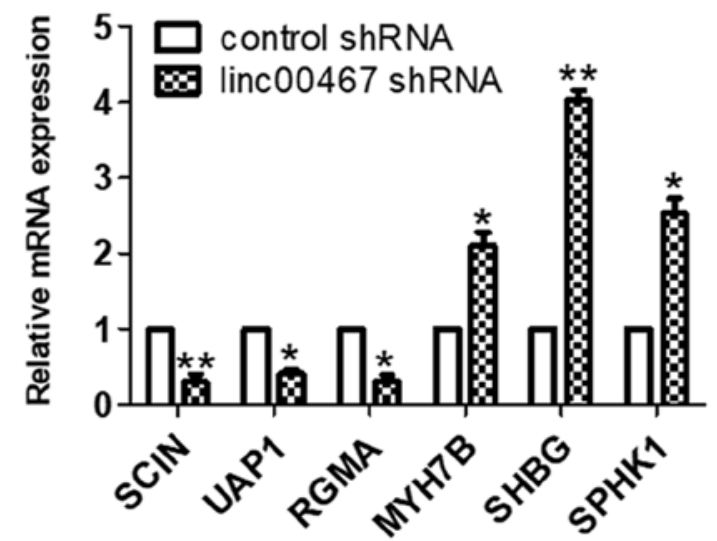

Figure 8. Gene expression profiling. (A and B) RNA transcriptome sequencing was used to analyse the gene expression profile in H1299 cells following linc00467 knockdown. A total of 625 differentially expressed transcripts were identified (471 upregulated transcripts and 154 downregulated transcripts, $\mid \log 2$ (fold change) $\mid>1$ and $\mathrm{P}<0.05$ ). A volcano plot and heat-map present all of the differentially expressed genes between linc00467-knockdown H1299 and control cells. (C and D) Reverse transcription quantitative polymerase chain reaction was used to verify the mRNA expression levels of 6 randomly selected genes in control shRNA vs. linc00467 shRNA-transfected (C) A549 and (D) H1299 cells. ${ }^{*} \mathrm{P}<0.05$ and ${ }^{* *} \mathrm{P}<0.01$. linc, long intergenic non-coding RNA; shRNA, short hairpin RNA. 
A

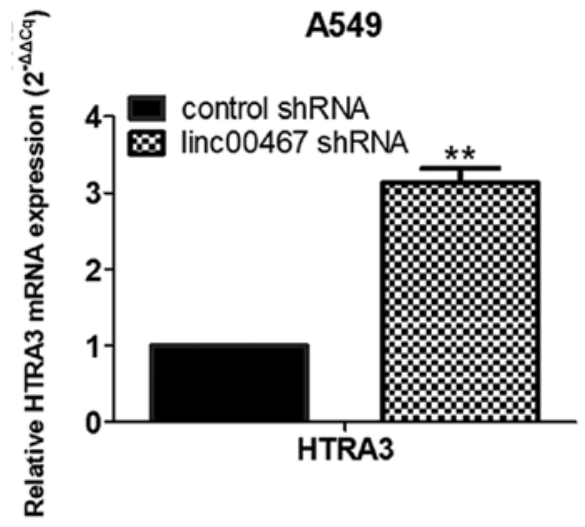

C

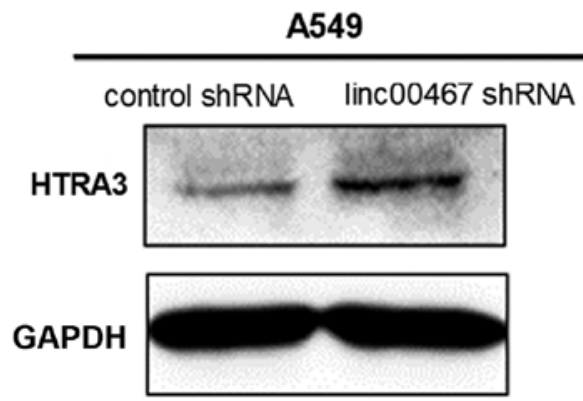

B

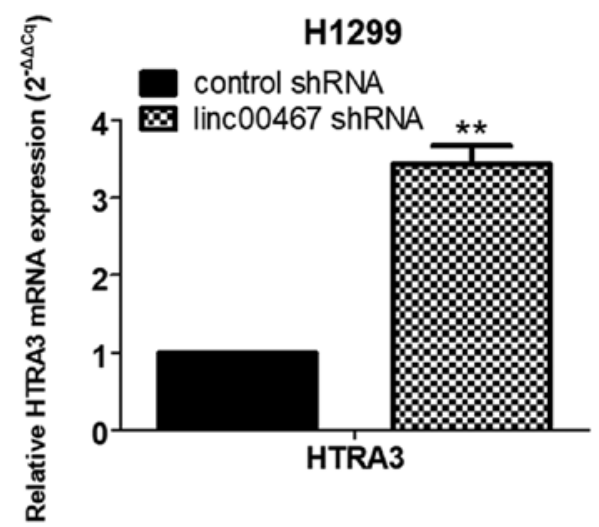

D

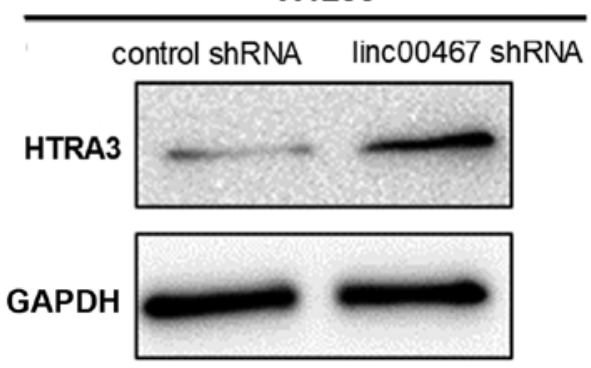

Figure 9. linc00467 regulates the mRNA and protein levels of HTRA3. (A and B) Changes in HTRA3 mRNA and protein expression levels in (A) A549 and (B) H1299 cells transfected with linc00467-shRNA as determined by reverse transcription quantitative polymerase chain reaction. (C and D) Changes in HTRA3 mRNA and protein expression levels in (C) A549 and (D) H1299 cells transfected with linc00467-shRNA as determined by western blot analysis. HTRA3 exhibited increased mRNA and protein expression levels in linc00467-knockdown A549 cells and H1299 cells compared with in control cells. The data were obtained from at least 3 independent experiments and are presented as the means \pm standard deviation. ${ }^{* *} \mathrm{P}<0.01$. linc, long intergenic non-coding RNA; HTRA3, HtrA serine peptidase 3; shRNA, short hairpin RNA.

verified that HTRA3 exhibited higher mRNA expression in linc00467-knockdown A549 cells and H1299 cells compared with the control cells using RT-qPCR, and protein levels were correspondingly elevated (Fig. 9A-D).

linc00467 represses HTRA3 expression by binding with $E Z H 2$. IncRNAs are able to bind RNA-binding proteins (RBPs) to regulate the expression of downstream genes. Therefore, the present study investigated whether linc00467 regulated HTRA3 expression by binding to RBPs. The probability of an interaction between linc00467 and RBPs was first determined using an lncRNA prediction website (http://annolnc.cbi.pku.edu.cn/index.jsp). The sequence of linc00467 was input into the AnnoLnc database, and entered into the protein interaction page; subsequently, the interaction score between IncRNA and protein could be predicted. The interaction score for linc00467 and EZH2 was 96.0705 , close to the maximum value of 100 . Whether linc00467 repressed HTRA3 transcription was next investigated by recruiting EZH2 to the HTRA3 promoter. EZH2 expression was first knocked down in A549 and H1299 cells using transfection with siRNA (Fig. 10A and B). In addition, western blot analysis was performed to measure HTRA3 protein expression levels when EZH2 was downregulated. The results indicated that HTRA 3 protein expression levels were increased in the EZH2-downregulated group compared with in the control group (Fig. 10C and D). Then, an RIP assay was performed to directly address whether linc00467 and EZH2 are binding partners. The RIP assay suggested that linc00467 was able to directly bind EZH2 in A549 and H1299 cells (Fig. 10E and 10F). In addition, a ChIP assay was used to verify that EZH2 bound to the promoter of HTRA3 (Fig. 10G). The results demonstrated that linc00467 repressed HTRA3 expression by binding with EZH2.

HTRA3 knockdown partially reverses linc00467-depletion induced inhibition of LAD cell proliferation, migration and invasion. Rescue experiments were used to examine the effect of inhibiting HTRA3 expression in linc00467-knockdown A549 and H1299 cells. The rescue experiments demonstrated that cell proliferation, migration and invasion were inhibited in linc00467-knockdown A549 and H1299 cells, whereas knockdown of HTRA3 partially reversed all of these effects (Fig. 11A-D).

HTRA3 is downregulated in LAD tissues and is associated with the clinical characteristics of $L A D$. The expression level of HTRA3 in LAD tissues was decreased compared with the adjacent normal lung tissues $(\mathrm{P}<0.001$; Fig. 12A). The association between HTRA3 expression and LAD clinical characteristics was additionally evaluated (Table II). Decreased HTRA3 expression was associated with larger tumour sizes $(\mathrm{P}=0.018$; Fig. 12B), increased lymph node metastasis $(\mathrm{P}=0.031$; Fig. 12C) and advanced TNM stages $(\mathrm{P}=0.012$; Fig. 12D). 

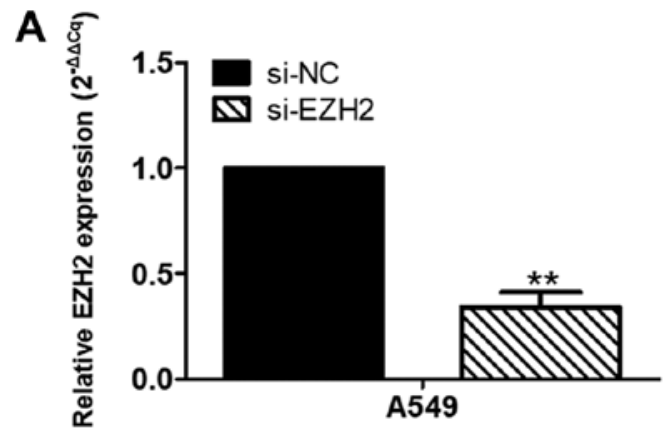

C

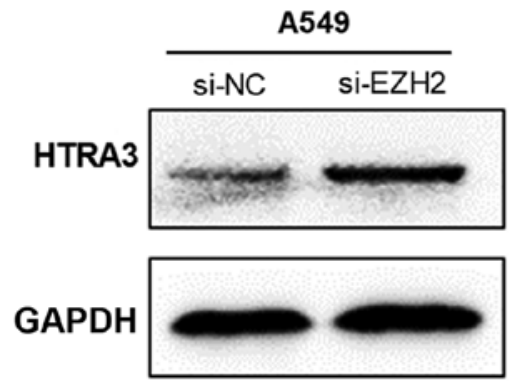

E

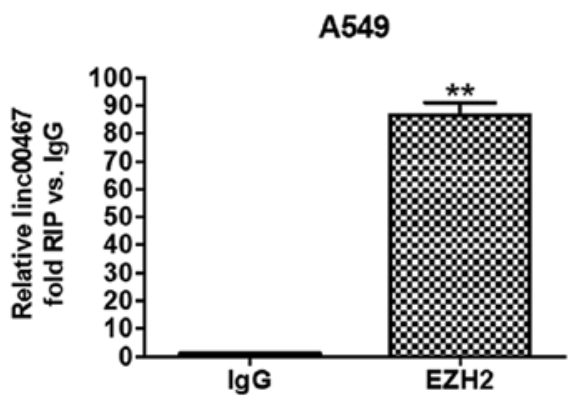

G

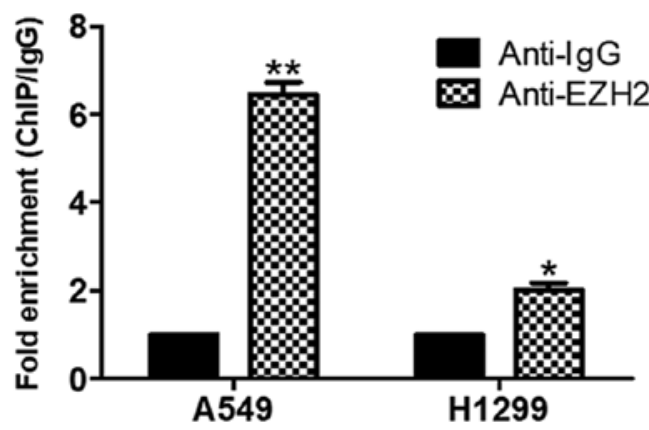

B

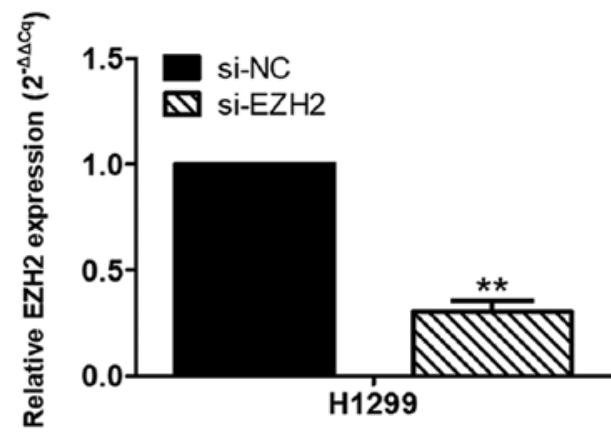

D

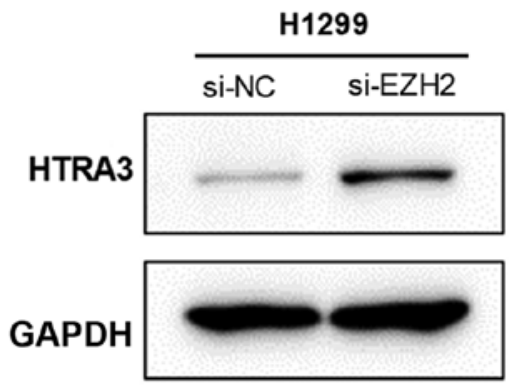

$\mathbf{F}$

H1299

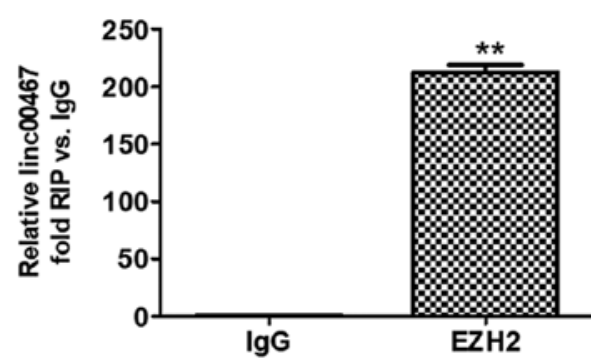

Figure 10. linc00467 represses HTRA3 expression by binding with EZH2. (A and B) EZH2 was knocked down in (A) A549 and (B) H1299 by transfection with siRNAs. The relative expression of EZH2 in siRNA-transfected A549 and H1299 cells is shown. (C and D) HTRA3 protein level changes in (C) A549 and (D) H1299 cells transfected with si-EZH2, as determined by western blot analysis. HTRA3 protein expression levels were increased in the EZH2-downregulated group compared with in the control group. (E and F) RNA immunoprecipitation experiments were performed in (E) A549 and (F) H1299 cells, and the coprecipitated RNA was subjected to RT-qPCR analysis for the presence of linc00467. The expression levels of linc00467 RNA are presented as the fold enrichment in EZH2 relative to the IgG immunoprecipitates. It was observed that linc00467 directly bound EZH2 in A549 and H1299 cells. (G) Chromatin immunoprecipitation RT-qPCR of EZH2 occupancy on the HTRA3 promoter in A549 and H1299 cells, with IgG as a negative control. The results indicated that EZH 2 was able to bind the HTRA3 promoter. The data were obtained from at least 3 independent experiments and are presented as the mean \pm standard deviation. ${ }^{*} \mathrm{P}<0.05$ and ${ }^{* *} \mathrm{P}<0.01$. linc, long intergenic non-coding RNA; HTRA3, HtrA serine peptidase 3; EZH2, histone-lysine N-methyltransferase EZH2; siRNA, small interfering RNA; RT-qPCR, reverse transcription quantitative polymerase chain reaction; NC, negative control.

\section{Discussion}

Previous studies have suggested that a large number of IncRNAs affect tumour cell proliferation, migration, invasion and apoptosis, and are closely associated with tumour development, progression and metastasis $(20,21)$. In the present study, bioinformatics analysis ofGEOand TCGA datasets demonstrated linc 00467 to be highly expressed in human lung cancer tissues. Subsequently, RT-qPCR analyses confirmed that linc 00467 was overexpressed in LAD tissues. In particular, the expression of linc00467 was significantly increased in larger and later-stage tumours. Additionally, it was identified that knockdown of 
A

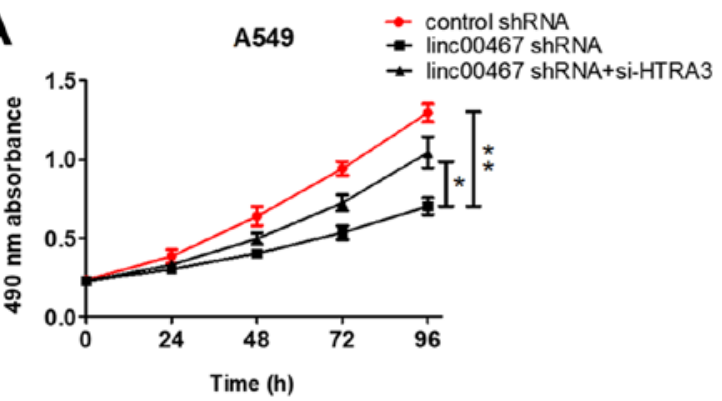

C
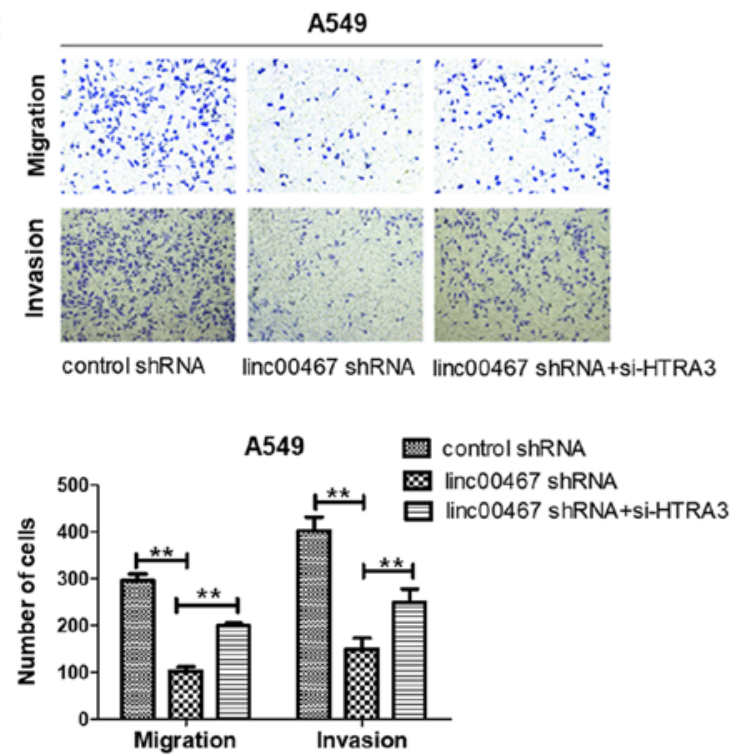
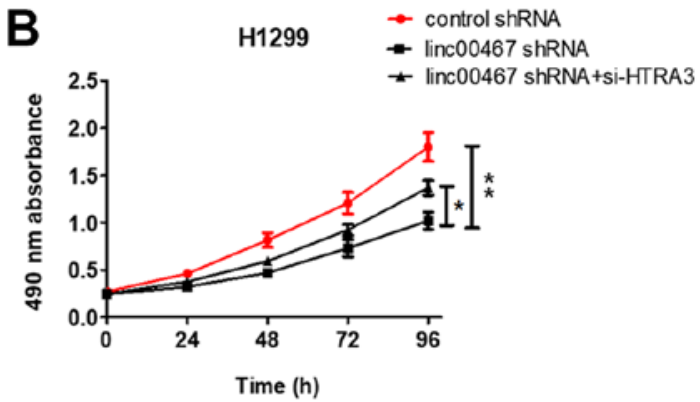

D
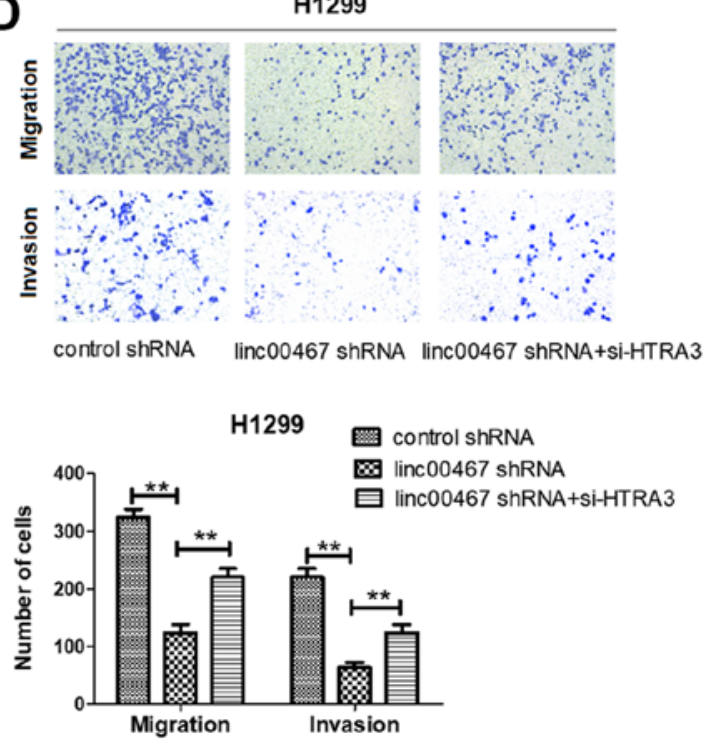

Figure 11. HTRA3 inhibition attenuates the inhibitory effect on proliferation, migration and invasion of LAD cells induced by linc00467 depletion. (A and B) Cell proliferation, migration and invasion were measured in (A) A549 and (B) H1299 cells transfected with control shRNA, linc00467 shRNA and linc00467 shRNA+si-HTRA3. (C and D) Cell proliferation, migration and invasion were inhibited in linc00467-knockdown (C) A549 and (D) H1299 cells, whereas knockdown of HTRA3 partially reversed all of these inhibitory effects. The data were obtained from at least 3 independent experiments and are presented as the mean \pm standard deviation. Magnification, $\mathrm{x} 100$. ${ }^{*} \mathrm{P}<0.05$ and ${ }^{* *} \mathrm{P}<0.01$. HTRA3, HtrA serine peptidase 3 ; linc, long intergenic non-coding RNA; shRNA, short hairpin RNA; siRNA, small interfering RNA; NC, negative control.

A

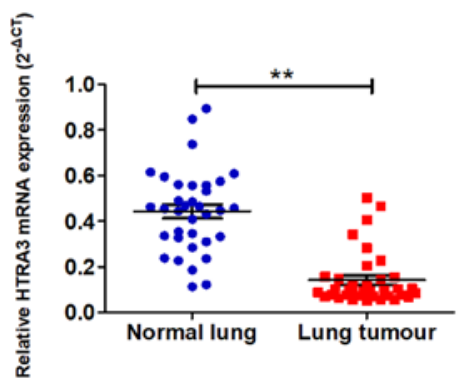

C

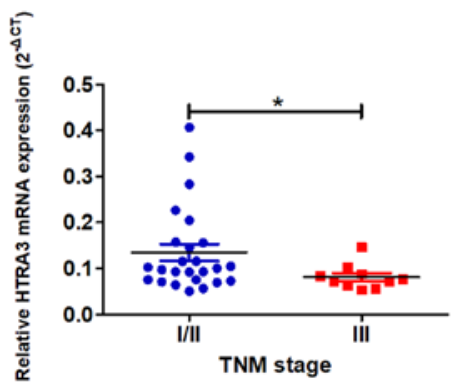

B

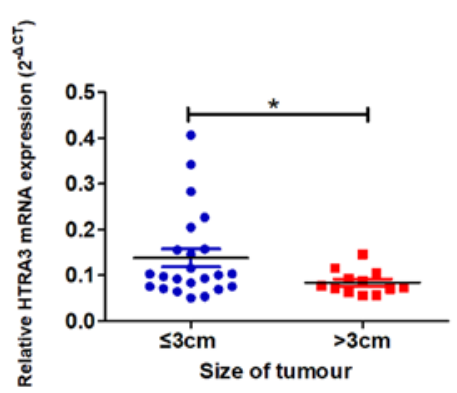

D

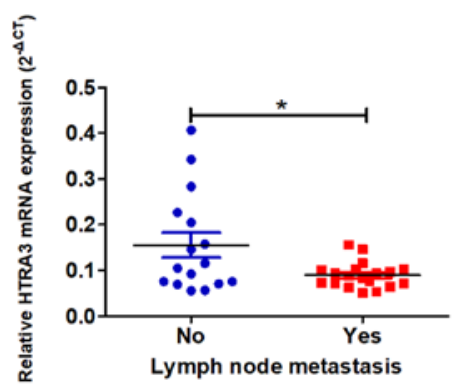

Figure 12. Relative expression and clinical significance of HTRA3 expression in LAD tissues. (A) The expression level of HTRA3 in LAD tissues was decreased compared with that in adjacent normal lung tissues. (B-D) HTRA3 expression was decreased in (B) tumours with a maximum diameter $>3 \mathrm{~cm}$, (C) stage III tumours and (D) high lymph node metastasis.. " $\mathrm{P}<0.05$ and $^{* *} \mathrm{P}<0.01$. HTRA3, HtrA serine peptidase 3; LAD, lung adenocarcinoma; linc, long intergenic non-coding RNA. 
Table II. Associations between HTRA3 expression and clinicopathological parameters of lung adenocarcinoma.

\begin{tabular}{|c|c|c|c|}
\hline \multirow[b]{2}{*}{ Clinicopathological parameters } & \multirow[b]{2}{*}{ Number of patients } & $\begin{array}{l}\text { HTRA3 mRNA expression } \\
\qquad\left(2^{-\Delta \mathrm{Cq}}\right)\end{array}$ & \multirow[b]{2}{*}{ P-value } \\
\hline & & Median \pm standard deviation & \\
\hline \multicolumn{4}{|l|}{ Sex } \\
\hline Male & 25 & $0.121 \pm 0.092$ & 0.856 \\
\hline Female & 10 & $0.115 \pm 0.055$ & \\
\hline \multicolumn{4}{|l|}{ Age, years } \\
\hline$\leq 65$ & 23 & $0.122 \pm 0.091$ & 0.736 \\
\hline$>65$ & 12 & $0.113 \pm 0.065$ & \\
\hline \multicolumn{4}{|l|}{ Size of tumor, cm } \\
\hline$\leq 3$ & 23 & $0.138 \pm 0.095$ & 0.018 \\
\hline$>3$ & 12 & $0.084 \pm 0.027$ & \\
\hline \multicolumn{4}{|l|}{ Differentiation } \\
\hline Well/moderate & 24 & $0.117 \pm 0.091$ & 0.799 \\
\hline Poor & 11 & $0.125 \pm 0.061$ & \\
\hline \multicolumn{4}{|l|}{ Lymph node metastasis } \\
\hline No & 16 & $0.155 \pm 0.109$ & 0.031 \\
\hline $\mathrm{N} 1-\mathrm{N} 3$ & 19 & $0.090 \pm 0.028$ & \\
\hline \multicolumn{4}{|l|}{ TNM stage } \\
\hline $\mathrm{I} / \mathrm{II}$ & 25 & $0.135 \pm 0.092$ & 0.012 \\
\hline III & 10 & $0.081 \pm 0.027$ & \\
\hline \multicolumn{4}{|l|}{ Smoking } \\
\hline Yes & 22 & $0.116 \pm 0.080$ & 0.738 \\
\hline No & 13 & $0.126 \pm 0.088$ & \\
\hline
\end{tabular}

HTRA3, HtrA serine peptidase 3; TNM, tumor node metastasis.

linc00467 inhibited LAD cell proliferation, migration and invasion, consistent with the results of Xia et al (22). These data suggested that linc00467 may exert an oncogenic function and serve an important role in LAD development. Consequently, it is necessary to explore the molecular mechanisms of linc00467 in LAD carcinogenesis.

lncRNAs do not encode proteins but are able to regulate the expression levels of genes at the epigenetic and transcriptional levels $(23,24)$. lncRNAs may be used as important regulatory factors to bind proteins and affect transcription. Previous studies have identified that lncRNAs recruit EZH2 (25) and WDR5 (26) to downstream target gene promoters to inhibit or activate target gene expression. EZH2 is encoded by the Drosophila EZH2 gene on human chromosome 7q35. This protein is the key subunit of the polycomb repressor complex 2 and mediates its catalytic action. The methylation of histone $\mathrm{H} 3$ mediated by EZH2 is associated with the occurrence and development of multiple tumours $(27,28)$. Initial studies first identified the role of EZH2 in hematologic malignancies (29), with subsequent studies identifying important roles in the development of prostate (30) and breast cancer (31), digestive system malignancies (32), head and neck (33) and lung cancer (34).

RNA sequencing of linc00467-knockdown LAD cells revealed that the anti-oncogene HTRA3 is a novel linc00467 target in LAD cells. HTRA3 is involved in important physiological processes, including apoptosis, cell signalling and mitochondrial homeostasis (35). Zhao et al (36) identified that HTRA3 may be used as a biomarker for the postoperative recurrence and prognosis of NSCLC. Wenta et al (37) additionally confirmed that HTRA3 should be considered a target of novel anticancer therapies. In the present study, it was identified that HTRA3 was downregulated in LAD compared to normal lung tissues, consistent with the results of the study by Zhao et al (36). Specifically, the expression of HTRA3 was significantly decreased in larger tumours, those with lymph node metastases and in later-stage tumours.

In the present study, RIP experiments confirmed that linc 00467 bound EZH2 in LAD cells, suggesting that linc00467 regulated underlying targets at the transcriptional level. In addition, EZH2 knockdown in LAD cells led to the upregulation of HTRA3, and ChIP assays revealed that EZH2 may be recruited to the HTRA3 promoter to repress HTRA3 transcription. Together, these data demonstrated that linc00467 served an important role in the EZH2-mediated repression of HTRA3 in LAD cells.

In summary, to the best of our knowledge, the present study is the first to demonstrate that linc00467 expression is upregulated in LAD tissues and that this lncRNA promoted LAD cell proliferation, migration and invasion. In addition, linc00467 was demonstrated to mediate oncogenic effects by binding with EZH2 and regulating HTRA3. The results of the present 
study strengthen the understanding of LAD pathogenesis, and support the hypothesis that linc00467 acts as an oncogene and serves an oncogenic role in LAD. However, there are certain limitations of the present study. Firstly, the biological roles of linc00467 were only examined in cell lines. Secondly, linc00467 may regulate multiple genes or miRNAs; for this reason, additional studies should be conducted to investigate the comprehensive linc00467 regulatory network.

\section{Acknowledgements}

Not applicable.

\section{Funding}

The present study was supported by the financial support from the National Natural Science Foundation of China (grant no. 81572273) and the Jiangsu Key Disease Special Research Projects (grant no. BL2013026).

\section{Availability of data and materials}

The datasets used and/or analyzed during the current study are available from the corresponding author on reasonable request.

\section{Authors' contributions}

XW and YS conceived and designed the experiment. XW wrote the manuscript. XW, HL, KS, XP and YW performed the experiments. XW and TL analyzed the data. XW and YS revised the manuscript. All authors read and approved the final version of the manuscript.

\section{Ethics approval and consent to participate}

The present study was approved by the Research Ethics Committee of the Jinling Clinical Medical College of Nanjing Medical University (Nanjing, China). All of the participants provided written informed consent form and agreed to the use of their samples in scientific research.

\section{Patient consent for publication}

All of the participants provided written informed consent form and agreed to the use of their samples in scientific research.

\section{Competing interests}

All authors declare that they have no competing interests.

\section{References}

1. Chen W, Zheng R, Baade PD, Zhang S, Zeng H, Bray F, Jemal A, Yu XQ and He J: Cancer statistics in China, 2015. CA Cancer J Clin 66: 115-132, 2016.

2. D'Antonio C, Passaro A, Gori B, Del Signore E, Migliorino MR, Ricciardi S, Fulvi A and de Marinis F: Bone and brain metastasis in lung cancer: Recent advances in therapeutic strategies. Ther Adv Med Oncol 6: 101-114,2014.

3. Siegel R, Ma J, Zou Z and Jemal A: Cancer statistics, 2014. CA Cancer J Clin 64: 9-29, 2014
4. Wang PQ, Wu YX, Zhong XD, Liu B and Qiao G: Prognostic significance of overexpressed long non-coding RNA TUG1 in patients with clear cell renal cell carcinoma. Eur Rev Med Pharmacol Sci 21: 82-86, 2017

5. Wang Y, Zhang W, Wang Y and Wang S: HOXD-AS1 promotes cell proliferation, migration and invasion through miR-608/FZD4 axis in ovarian cancer. Am J Cancer Res 8: 170-182, 2018.

6. Ricciuti B, Mencaroni C, Paglialunga L, Paciullo F, Crino L, Chiari R and Metro G: Long noncoding RNAs: New insights into non-small cell lung cancer biology, diagnosis and therapy. Med Oncol 33: 18, 2016.

7. Zhang Y and Tang L: The application of lncRNAs in cancer treatment and diagnosis. Recent Pat Anticancer Drug Discov 13: 292-301,2018.

8. Chen L, Dzakah EE and Shan G: Targetable long non-coding RNAs in cancer treatments. Cancer Lett 418: 119-124, 2018.

9. Chandra Gupta S and Nandan Tripathi Y: Potential of long non-coding RNAs in cancer patients: From biomarkers to therapeutic targets. Int J Cancer 140: 1955-1967, 2017.

10. Atmadibrata B, Liu PY, Sokolowski N, Zhang L, Wong M, Tee AE, Marshall GM and Liu T: The novel long noncoding RNA linc00467 promotes cell survival but is down'regulated by N-Myc. Plos One 9: e88112, 2014.

11. Singh H, Li Y, Fuller PJ, Harrison C, Rao J, Stephens AN and Nie G: HtrA3 is downregulated in cancer cell lines and significantly reduced in primary serous and granulosa cell ovarian tumors. J Cancer 4: 152-164, 2013.

12. Li Y, Gong L, Qi R, Sun Q, Xia X, He H, Ren J, Zhu O and Zhou D: Paeoniflorin suppresses pancreatic cancer cell growth by upregulating HTRA3 expression. Drug Des Devel Ther 11: 2481-2491,2017.

13. Yin Y, Wu M, Nie G, Wang K, Wei J, Zhao M and Chen Q: HtrA3 is negatively correlated with lymph node metastasis in invasive ductal breast cancer. Tumour Biol 34: 3611-3617, 2013.

14. Ritchie ME, Phipson B, Wu D, Hu Y, Law CW, Shi W and Smyth GK: Limma powers differential expression analyses for RNA-sequencing and microarray studies. Nucleic Acids Res 43: e47, 2015.

15. Kim D, Langmead B and Salzberg SL: HISAT: A fast spliced aligner with low memory requirements. Nat Methods 12: 357-360, 2015.

16. Pertea M, Pertea GM, Antonescu CM, Chang TC, Mendell JT and Salzberg SL: StringTie enables improved reconstruction of a transcriptome from RNA-seq reads. Nat Biotechnol 33: 290-295, 2015.

17. Pertea M, Kim D,Pertea GM, Leek JT and Salzberg SL: Transcript-level expression analysis of RNA-seq experiments with HISAT, StringTie and Ballgown. Nat Protoc 11: 1650-1667, 2016.

18. Travis WD, Brambilla E, Noguchi M, Nicholson AG, Geisinger K, Yatabe Y, Powell CA, Beer D, Riely G, Garg K, et al: International Association for the Study of Lung Cancer/American Thoracic Society/European Respiratory Society: International multidisciplinary classification of lung adenocarcinoma: Executive summary. Proc Am Thorac Soc 8: 381-385, 2011.

19. Livak KJ and Schmittgen TD: Analysis of relative gene expression data using real-time quantitative PCR and the 2(-Delta Delta C(T)) method. Methods 25: 402-408, 2001

20. Malek E, Jagannathan S and Driscoll JJ: Correlation of long non-coding RNA expression with metastasis, drug resistance and clinical outcome in cancer. Oncotarget 5: 8027-8038, 2014.

21. Chen J, Wang R, Zhang K and Chen LB: Long non-coding RNAs in non-small cell lung cancer as biomarkers and therapeutic targets. J Cell Mol Med 18: 2425-2436, 2014.

22. Xia H, Jing $\mathrm{H}, \mathrm{Li} \mathrm{Y}$ and $\mathrm{Lv} \mathrm{X}$ : Long noncoding RNA HOXD-AS1 promotes non-small cell lung cancer migration and invasion through regulating miR-133b/MMP9 axis. Biomed Pharmacother 106: 156-162, 2018.

23. Quinn JJ and Chang HY: Unique features of long non-coding RNA biogenesis and function. Nat Rev Genet 17: 47-62, 2016.

24. Di Gesualdo F, Capaccioli S and Lulli M: A pathophysiological view of the long non-coding RNA world. Oncotarget 5: 10976-10996, 2014.

25. Yang L, Ge D, Chen X, Qiu J, Yin Z, Zheng S and Jiang C: FOXP4-AS1 participates in the development and progression of osteosarcoma by downregulating LATS1 via binding to LSD1 and EZH2. Biochem Biophys Res Commun 502: 493-500, 2018.

26. Sun TT, He J, Liang Q, Ren LL, Yan TT, Yu TC, Tang JY, Bao YJ, $\mathrm{Hu} \mathrm{Y}$ and Lin Y, et al: A novel lncRNA GClnc1 promotes gastric carcinogenesis and may act as a modular scaffold of WDR5 and KAT2A complexes to specify the histone modification pattern. Cancer Discov 6: 784-801, 2016. 
27. Takashina T, Kinoshita I, Kikuchi J, Shimizu Y, SakakibaraKonishi J, Oizumi S, Nishimura M and Dosaka-Akita H: Combined inhibition of EZH2 and histone deacetylases as a potential epigenetic therapy for non-small-cell lung cancer cells. Cancer Sci 107: 955-962, 2016.

28. Liu S, Chen D, Shen W, Chen L, Yu A, Fu H, Sun K and Sun X: EZH2 mediates the regulation of S100A4 on E-cadherin expression and the proliferation, migration of gastric cancer cells Hepatogastroenterology 62: 737-741, 2015.

29. McDevitt MA: Clinical applications of epigenetic markers and epigenetic profiling in myeloid malignancies. Semin Oncol 39: $109-122,2012$

30. van Leenders GJ, Dukers D, Hessels D, van den Kieboom SW, Hulsbergen CA, Witjes JA, Otte AP, Meijer CJ and Raaphorst FM: Polycomb-group oncogenes EZH2,BMIl and RINGl are overexpressed in prostate cancer with adverse pathologic and clinical features. Eur Urol 52: 455-463, 2007.

31. Yoo KH and Hennighausen L: EZH2 methyltransferase and H3K27 methylation in breast cancer. Int J Biol Sci 8: 59-65, 2012.

32. Benard A, Goossens-Beumer IJ, van Hoesel AQ, Horati H, Putter H, Zeestraten EC, van de Velde CJ and Kuppen PJ: Prognostic value of polycomb proteins EZH2, BMI1 and SUZ12 and histone modification H3K27me3 in colorectal cancer. PLoS One 9: e108265, 2014

33. Gannon OM, Merida de Long L, Endo-Munoz L, HazarRethinam M and Saunders NA: Dysregulation of the repressive H3K 27 trimethylation mark in head and neck squamous cell carcinoma contributes to dysregulated squamous differentiation. Clin Cancer Res 19: 428-441, 2013.
34. Saito M, Saito K, Shiraishi K, Maeda D, Suzuki H, Minamiya Y, Kono K, Kohno T and Goto A: Identification of candidate responders for anti-PD-L1/PD-1 immunotherapy, Rova-T therapy, or EZH2 inhibitory therapy in small-cell lung cancer. Mol Clin Oncol 8: 310-314, 2018.

35. Clausen T, Southan C and Ehrmann M: The HtrA family of proteases: Implications for protein composition and cell fate. Mol Cell 10: 443-455, 2002

36. Zhao J, Zhang J, Zhang X, Feng $M$ and Qu J: High temperature requirement A3 (HTRA3) expression predicts postoperative recurrence and survival in patients with non-small-cell lung cancer. Oncotarget 7: 40725-40734, 2016.

37. Wenta T, Zurawa-Janicka D, Rychlowski M, Jarzab M, Glaza P, Lipinska A, Bienkowska-Szewczyk K, Herman-Antosiewicz A, Skorko-Glonek J and Lipinska B: HtrA3 is a cellular partner of cytoskeleton proteins and TCP1 $\alpha$ chaperonin. J Proteomics 177: 88-111, 2018.

This work is licensed under a Creative Commons Attribution-NonCommercial-NoDerivatives 4.0 International (CC BY-NC-ND 4.0) License. 